\title{
Settlement mechanism and improvement of thick silty sand layer overlying mud foundation
}

Bingyi Li PhD

Jiangsu Technology Industrialization and Research Center of Ecological Road Engineering, Suzhou University of Science and Technology, Suzhou, China (corresponding author: bylee17@163.com)

Xiao Cheng PhD

School of Civil Engineering \& Architecture, NingboTech University, Ningbo, China

\author{
Yanbo Fan MSc \\ State Grid Zhenjiang Power Supply Company, Zhenjiang, China \\ Bin Qian MSc \\ Geotechnical Engineering Department, Nanjing Hydraulic Research \\ Institute, Nanjing, China \\ Yonghui Chen PhD \\ Key Laboratory of Ministry of Education for Geomechanics and \\ Embankment Engineering, Hohai University, Nanjing, China
}

Many highways have been built on the eastern coast of China in the past decades. Recently, some engineering problems have emerged after long-term operation. Due to the different properties between the underlying soil and bridge pile foundations, the problem of bumping at the bridge head is inevitable. To study the potential causes and provide insight for future improvement, the settlement of typical highways in the Hangzhou Bay area, which had been open to traffic for more than 10 years, was investigated. After an analytical calculation with the verification of the numerical method and field data, it was indicated that long-term deformation was mainly caused by the poor properties of the lower of the two layers that make up the underlying soil. The trend of the variation of the lower layer keeps increasing at a slow rate during the construction period, resulting in sustained and rapid changes during the following years. Different kinds of ground improvement such as lightweight materials and soil-cement columns generated by deep mixing or jet grouting methods are discussed. The improvement of the lower layer will be more effective. With the analytical method, it is convenient and efficient to calculate and analyse the settlement at different periods, which is significant for design.

Keywords: foundations/geotechnical engineering/road and highways

\section{Notation}

A

equivalent consolidation coefficient of ground improved

by soil-cement columns

c cohesion

$c_{v i} \quad$ coefficient of consolidation for $i$ th layer

$d_{1} \quad$ density of replaced lightweight materials

$d_{\mathrm{s}} \quad$ density of original embankment soil

E Young's modulus

$E_{\mathrm{c}} \quad$ constrained modulus of columns

$\overline{E_{\mathrm{s}}(r)}$ average constrained modulus of surrounding soil

$H$ total thickness of foundation

$H^{\prime} \quad$ entire height of embankment filling

$H_{1} \quad$ thickness of upper layer

$\mathrm{H}_{2} \quad$ thickness of lower layer

$h \quad$ thickness of replaced lightweight materials

$k_{i} \quad$ permeability coefficient of $i$ th layer

$k_{v 1} \quad$ vertical permeability of soil

$m_{v i} \quad$ coefficient of consolidation volume compressibility for $i$ th layer

radius ratio

diameter of single column

space between the columns

final settlement

modified final settlement

settlement at time $t$
$T_{\mathrm{c}} \quad$ construction time factor

$T_{v} \quad$ time factor

$t \quad$ time elapse

$U$ average degree of consolidation

$u \quad$ excess pore water pressure

Y constrained modulus ratio of the soil-cement column to the surrounding soil

depth in foundation

modification coefficient of settlement with replacement wet density

vertical total stress increase

additional stress at surface of foundation

additional stress at interface of two layers

additional stress at bottom of the foundation

Poisson's ratio

friction angle

dilation angle

\section{Introduction}

With the development of society and economy, an increasing number of highways have been built along the eastern coast of China in recent decades. Meanwhile, with the initiative of 'the Silk Road Economic Belt and the 21st-Century Maritime Silk Road' proposed by the Chinese government, the Hangzhou Bay area plays a vital role not only in road transportation but also in shipping 
logistics. In the construction of highways and any other roads, the controlling of settlements can be a significant issue. The region around Hangzhou Bay is a typical location along the eastern coast suffering from increasing traffic. However, some highways built over 10 years ago still suffer from severe settlement problems, which causes problems for engineers and some related departments.

Due to the historical and natural evolution, the typical geological distribution in the vertical direction in the Hangzhou Bay region is a thick silty sand layer overlying a mud layer. The engineering properties of these two soil layers are different, causing a complicated deformation and settlement behaviour. The settlement and consolidation behaviour of the foundation may also be influenced by the properties of the silty sand, which is considered a granular material. The mechanical properties of granular materials under a different consolidation have been studied by several groups (Fourie and Tshabalala, 2005; Kato et al., 2001; Rahman et al., 2018). The discrete-element method has also been used to simulate the behaviour of materials (Nguyen et al., 2017; Rahman et al., 2018). On the other hand, the consolidation behaviour and long-term settlement of embankments on soft soil have been investigated using numerical analysis, such as the finite-element method (Huang et al., 2006). However, few studies have been conducted to illustrate the settlement mechanism of a thick silty sand layer overlying a mud layer, considering the different properties of the two layers, especially in road embankments.

Regarding research on the double-layer foundation, Terzaghi and Peck (1948) first came up with a stress-transfer model when investigating the settlement of a double-layer foundation on sand overlying soft clay and the proposed model of stress diffusion. Moreover, Meyerhof (1974) and Hanna and Meyerhof (1980) analysed the ultimate bearing capacity of a soil foundation overlying soft clay and put forward a punching shear failure model. The bearing capacity of the double-layered foundation has been evaluated by modelling tests (Kenny et al., 1997; Okamura et al., 1997). The finite-element method has been applied to analyse the failure modes of an upper sand foundation (Griffiths 1982; Eshkevari et al., 2019). Also, the finite-difference method has been employed for a layered soil foundation with sand overlying clay (Burd and Fryman 1997; Zheng et al., 2016). On the other hand, the problem of settlement is an important issue that needs to be considered. Schiffmann and Stein (1970) initially obtained a mathematical solution for a layered consolidation problem. Zhu and Yin $(1999,2005)$ presented several analytical solution charts for double soil layers under ramp loading with different depths and ramp loads. A long-term settlement of peat ground under the embankment was found, and simulated, by Tyurin and Nevzorov (2017) taking soft soil creep into account. Centrifuge physical modelling and numerical analysis have been performed to study the long-term consolidation of soft clay under embankment loading (Yadav et al., 2019). Xie et al. (1999) introduced an analytical solution for a two-layered soil with partially drained boundaries. Miao et al. (2008) proposed a solution on soft clayey soils reinforced by deep mixed columns. Analytical solutions have been proposed for saturated multi-layered soil under time-dependent loading (Kim et al., 2020). However, the previous conclusions were usually used to analyse the consolidation with parameters based on some assumptions. Few solutions were applied in practical engineering. In real engineering conditions, settlement should also be taken into consideration. It can be more significant to determine the settlement value after filling construction. In fact, although it may take a long time to complete the consolidation process, what engineers may be more concerned about is whether the settlement post-construction is less than the criteria value in the design standard. Although numerical simulation methods can be used in the analysis of the settlement and consolidation properties of a similar layered foundation under embankments ( $\mathrm{Li}$ et al., 2017), it is timeconsuming, especially when the construction design in different geologic conditions need to be analysed. Thus, some simple and effective analysis methods should be used to illustrate the settlement and consolidation properties of the foundation.

In this paper, to study the settlement mechanism of a thick silty sand layer overlying a mud foundation in a practical scenario, site investigation, theoretic solutions, field monitoring and a numerical method were applied. The settlement of pavements and embankments in Hangzhou Bay region was first investigated. With a verified analytical method, the pore water pressure (PWP), consolidation degree and displacement of each layer were analysed. The cause and mechanism of long-term and continuous settlement were illustrated. With the analytical method, it was convenient and efficient to calculate and analyse the settlement at different periods; this is significant for road and geotechnical designs.

\section{Site condition in Hangzhou Bay area}

\section{Typical soil layer distribution}

The Hangzhou Bay is a funnel-shaped estuary, which is located at the north-east of Zhejiang province, China, where the Qiantang River discharges into the sea (shown in Figure 1). Due to the

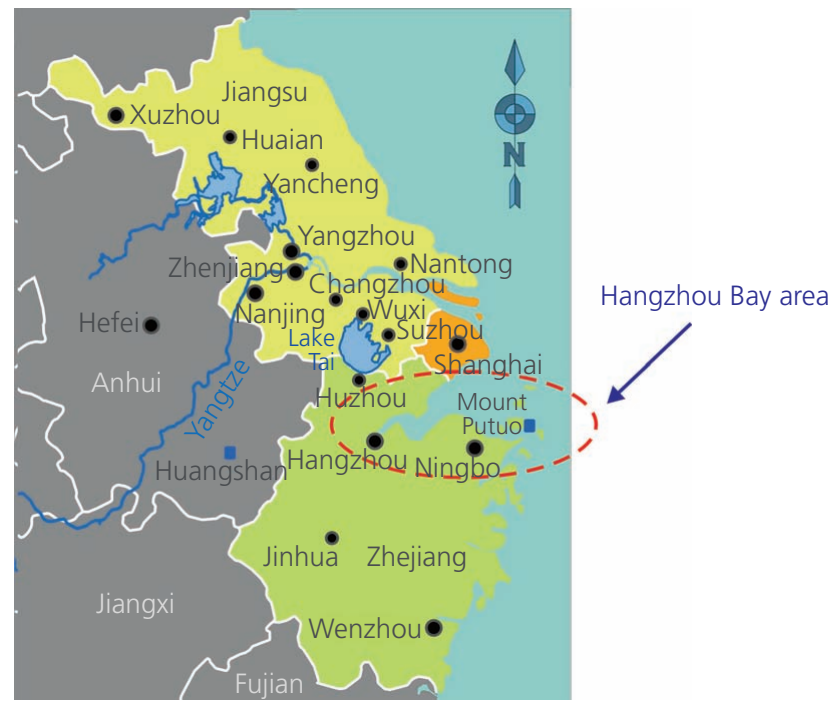

Figure 1. Location of Hangzhou Bay region 
Geotechnical Research

Volume 9 Issue 1
Settlement mechanism and improvement

of thick silty sand layer overlying mud

foundation

Li, Cheng, Fan, Qian and Chen long-term and complicated hydraulic process, the soil layers experienced river evolution and marine deposits (Liu et al., 2017). Finally, the Hangzhou Bay area has turned out to be a typical distribution of double soil layers.

The typical geological condition in Hangzhou Bay is illustrated in Figure 2.The typical layer distribution is summarised from a lot of site investigations in the Hangzhou Bay region during the constructions of roads or building engineering (ZIC, 2013).

The surface layer is usually made up of silty and sandy soil, and the thickness is generally more than $10 \mathrm{~m}$. Below that layer, a layer of soft soil is unfortunately muddy. The upper silty sandy soil has relatively low compressibility and high hydraulic

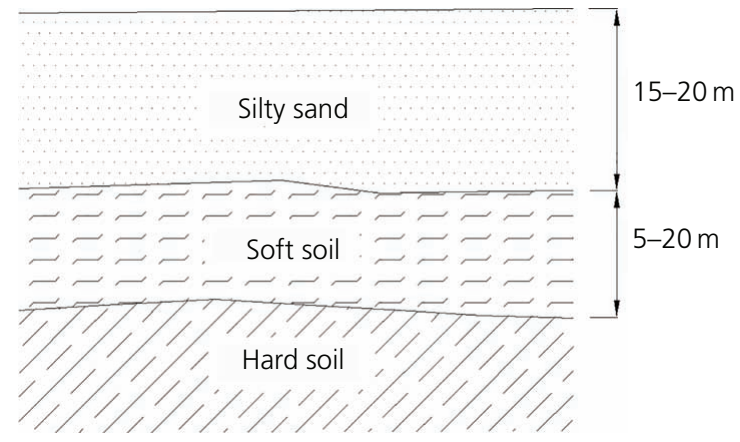

Figure 2. Typical distribution of soil layers conductivity, while the underlying clay has high compressibility and lower hydraulic conductivity.

\section{Typical problems of highway embankments in Hangzhou} Bay area

\section{Long-term settlement and problems of pavements and} embankments

From the data collected by the monitoring department in 2012, 10 years after construction completion and opening to traffic, the pavements of the Hang-Jin-Qu highway (marked in Figure 3) have kept settling at a high rate.

The Xiaoshan airport highway (marked in Figure 3) is vital in the transportation system. Frequently, cracks and potholes caused by the differential settlements would make drivers uncomfortable which undoubtedly causes danger (as shown in Figure 4).

A typical section of the Hangzhou-Quzhou highway, the Jiefanghe Bridge (marked in Figure 3), was chosen to be analysed in terms of its settlement on the bridge. As can be seen from Figure 5, the data illustrated that there were some large settlements on both sides of the bridge head. On the left and right traffic lanes as well as on the asphalt pavement surface, there were some cracks. The settlement value ranged from 30 to $70 \mathrm{~cm}$, which was more than the design value.

\section{Settlement rate}

According to the survey of the Hangzhou-Quzhou highway at 10 years after construction, $55 \%$ of the section has completed the settlement process and the consolidation rate was $0 \sim 0.5 \mathrm{~mm} / \mathrm{month}$

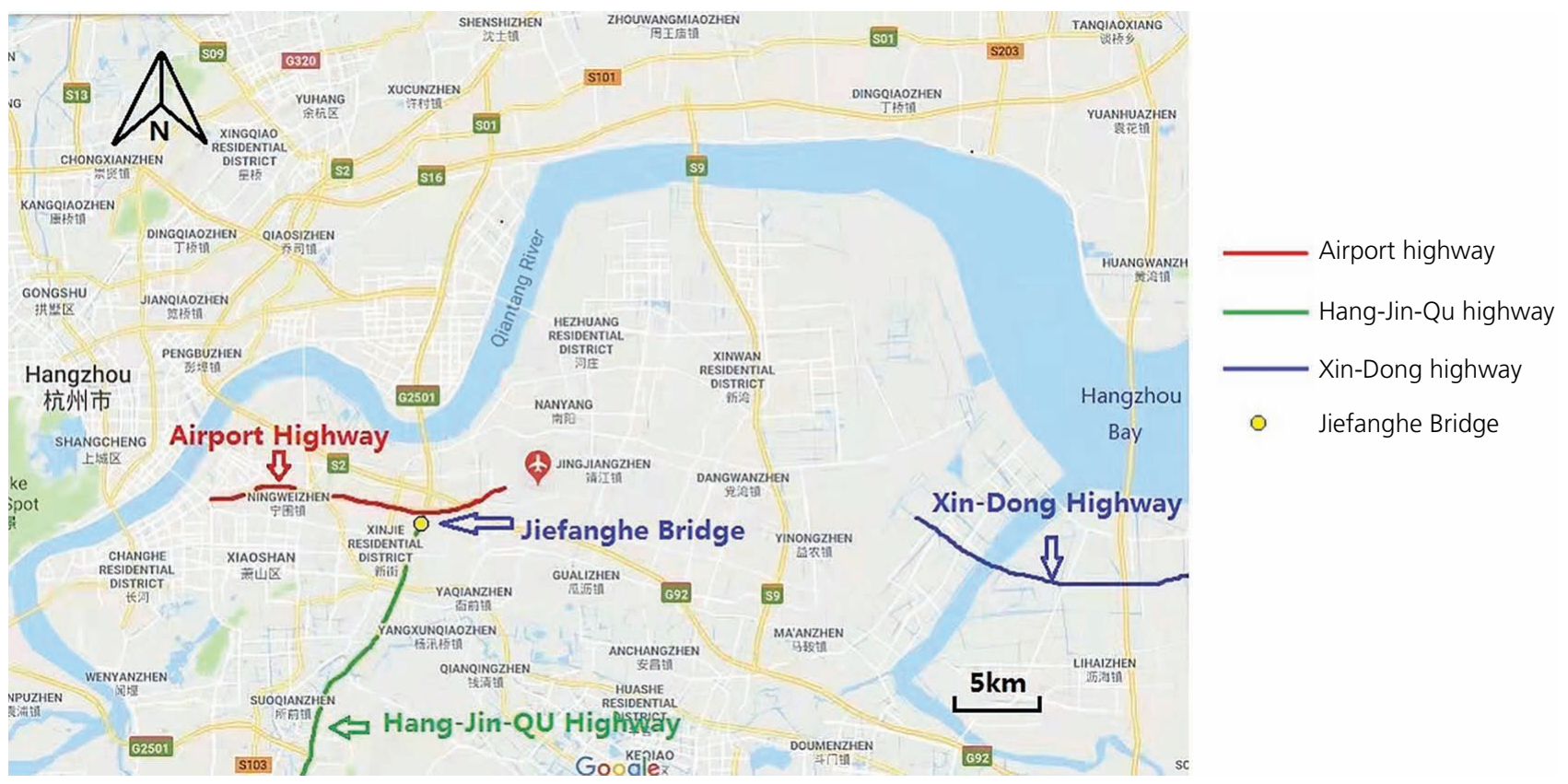

Figure 3. Location of highway projects mentioned in this study 
Settlement mechanism and improvement of thick silty sand layer overlying mud

foundation

Li, Cheng, Fan, Qian and Chen

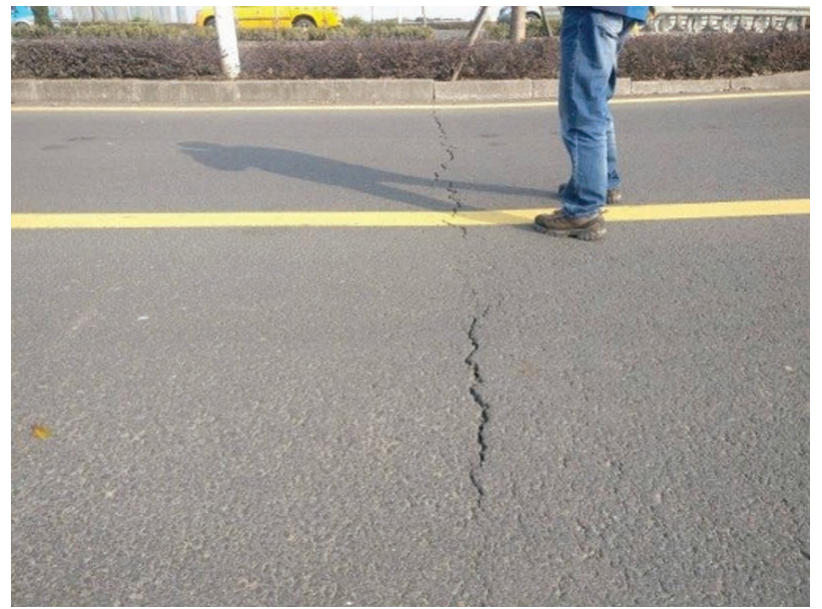

(a)

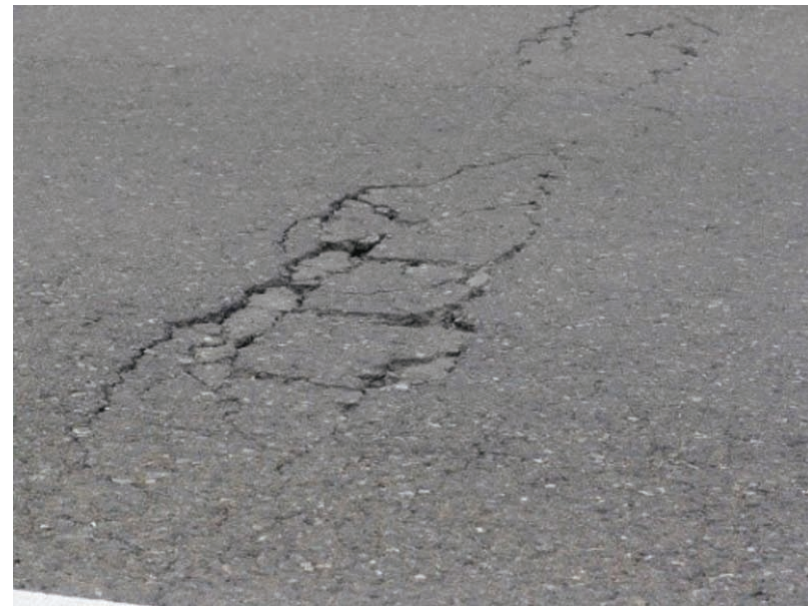

(b)

Figure 4. Problems on pavement of airport highway: (a) cracks; (b) potholes

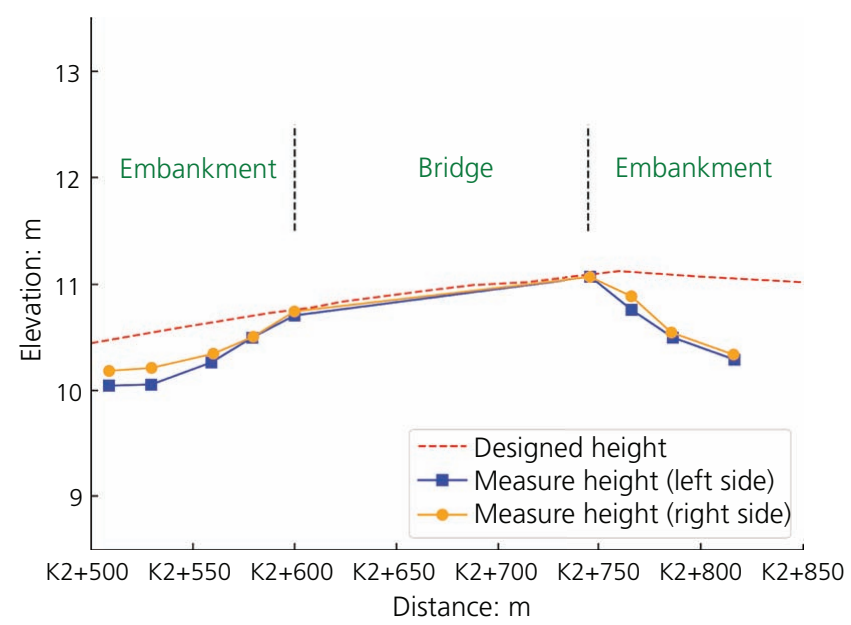

Figure 5. Pavement line graph of Jiefanghe Bridge $(K 2+645)$
(Figure 6), while the rest showed settlement rates of more than $0.50 \mathrm{~mm} / \mathrm{month}$, indicating that the settlement process was continuing. From the overall distribution, this paper illustrates that $90 \%$ of observation points were settling at a rate of less than $2.50 \mathrm{~mm}$ per month; however, the settlement of some points was more than $2.50 \mathrm{~mm}$ per month.

\section{Theoretic analysis}

It is necessary to study the cause and mechanism of long-term settlement. To have an insightful analysis of foundations in such geological conditions, sections with layers having different parameters and soil properties should be calculated. In this study, the analytical method was chosen to calculate the settlement and consolidation.

\section{Theoretical equations}

From previous research, there were some theoretic models to calculate the settlement and consolidation of double or multiple layers. Zhu and Yin (1999) figured out a series of formulas to calculate the consolidation of a double-layered system foundation:

$\frac{\partial u}{\partial t}=\left\{\begin{array}{l}c_{v 1} \frac{\partial^{2} u}{\partial z^{2}}+\frac{\partial \sigma}{\partial t}, 0 \leq z \leq H_{1} \\ c_{v 2} \frac{\partial^{2} u}{\partial z^{2}}+\frac{\partial \sigma}{\partial t}, H_{1} \leq z \leq H\end{array}\right.$

where $u$ is the excess PWP, $\sigma$ is the vertical total stress increase and $t$ is the time elapsed:

$$
\sigma(z, t)=\left\{\begin{array}{l}
\left(\sigma_{0}+\frac{\sigma_{1}-\sigma_{0}}{H_{1}} z\right) \min \left(1, \frac{t}{t_{\mathrm{c}}}\right) 0 \leq z \leq H_{1} \\
{\left[\sigma_{1}+\frac{\sigma_{2}-\sigma_{1}}{H_{2}}\left(z-H_{1}\right)\right] \min \left(1, \frac{t}{t_{\mathrm{c}}}\right) H_{1} \leq z \leq H}
\end{array}\right.
$$

where $\sigma_{0}, \sigma_{1}$ and $\sigma_{2}$ is the additional stress at the surface of the foundation $(z=0)$, the interface of two layers $\left(z=H_{1}\right)$ and the bottom of the foundation when construction is completed. The minimum function means that the output is the smaller value.

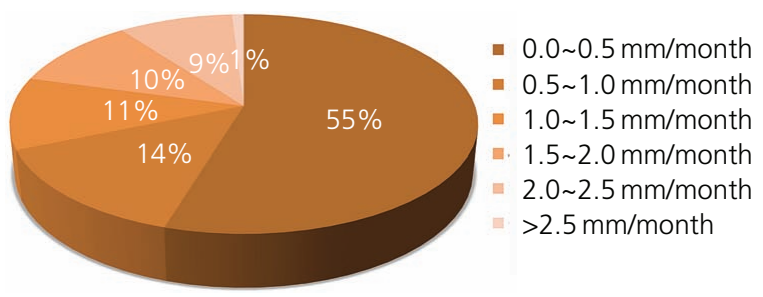

Figure 6. Distribution of different settlement rates at observation points 
Settlement mechanism and improvement

of thick silty sand layer overlying mud

foundation

Li, Cheng, Fan, Qian and Chen
According to the section geological profiles of the Hangzhou Bay region, the soil below the soft soil layer is clay, so the bottom side is assumed to be impermeable. Then, the boundary condition was as follows:

3. $\left\{\begin{array}{l}u(0, t)=0 \\ \left.\frac{\partial}{\partial z}\right|_{z=H}=0 \\ u(z, 0)=0\end{array}\right.$

At the interface of the two layers, there was a continuous condition.

$\left\{\begin{array}{l}\left.u(z, t)\right|_{z=H_{1}^{-}}=\left.u(z, t)\right|_{z=H_{1}^{+}} \\ \left.k_{1} \frac{\partial u(z, t)}{\partial z}\right|_{z=H_{1}^{-}}=\left.k_{2} \frac{\partial u(z, t)}{\partial z}\right|_{z=H_{1}^{+}}\end{array}\right.$

Using the method in the papers of of Zhu and Yin (1999, 2005), the following dimensionless parameters were introduced: time factor, $T_{v}$

5. $\quad T_{v}=\frac{c_{v 1} c_{v 2} t}{\left(H_{1} \sqrt{c_{v 2}}+H_{2} \sqrt{c_{v 1}}\right)}$

and construction time, $T_{\mathrm{c}}$

6. $T_{\mathrm{c}}=\frac{c_{v 1} c_{v 2} t}{\left(H_{1} \sqrt{c_{v 2}}+H_{2} \sqrt{c_{v 1}}\right)}$

Parameters $p, q, \alpha$ and $\beta$ can be calculated as follows:

7.

$p=\frac{\sqrt{k_{2} m_{v 2}}-\sqrt{k_{1} m_{v 1}}}{\sqrt{k_{2} m_{v 2}}+\sqrt{k_{1} m_{v 1}}}$

8.

$q=\frac{H_{1} \sqrt{c_{v 2}}-H_{2} \sqrt{c_{v 1}}}{H_{1} \sqrt{c_{v 2}}+H_{2} \sqrt{c_{v 1}}}$

9. $\alpha=\frac{H_{1} \sqrt{c_{v 2}}}{H_{1} \sqrt{c_{v 2}}+H_{2} \sqrt{c_{v 1}}}$

10.

$\beta=\frac{H_{2} \sqrt{c_{v 1}}}{H_{1} \sqrt{c_{v 2}}+H_{2} \sqrt{c_{v 1}}}$

The solution of the equation is
11. $u\left(z, T_{v}\right)=\sum_{n=1}^{+\infty} T_{n}\left(T_{v}\right) Z_{n}(z)$

where

$$
T_{n}\left(T_{v}\right)= \begin{cases}\frac{b_{n}}{\lambda_{n}^{3} T_{\mathrm{c}}}\left[1-\exp \left(-\lambda_{n}^{2} T_{\mathrm{c}}\right)\right] & T_{v} \leq T_{\mathrm{c}} \\ \frac{b_{n}}{\lambda_{n}^{3} T_{\mathrm{c}}}\left[1-\exp \left[-\lambda_{n}^{2}\left(T_{v}-T_{\mathrm{c}}\right)\right)\right] & T_{v}>T_{\mathrm{c}}\end{cases}
$$

$b_{n}=\frac{\left[\frac{m_{v 1} H_{1}}{\alpha \sin \left(\lambda_{n} \alpha\right)}\right] \sigma_{0}+\left[\frac{m_{v 1} H_{1}}{\alpha^{2} \lambda_{n}}\right]\left(\sigma_{1}-\sigma_{0}\right)+\left[m_{v 1} H_{1}\left[\frac{\cos \left(\lambda_{n} \beta\right)-1}{\beta^{2} \lambda_{n} \cos \left(\lambda_{n} \beta\right)}\right]\right]\left(\sigma_{1}-\sigma_{2}\right)}{\left[\frac{m_{v 2} H_{1}}{2 \sin ^{2}\left(\lambda_{n} \alpha\right)}\right]+\left[\frac{m_{v 2} H_{2}}{2 \cos ^{2}\left(\lambda_{n} \beta\right)}\right]}$ 13.

14.

$$
Z_{n}= \begin{cases}\frac{\sin \left(\lambda_{n} \alpha \frac{z}{H_{1}}\right)}{\sin \left(\lambda_{n} \alpha\right)} & 0 \leq z \leq H_{1} \\ \frac{\cos \left(\lambda_{n} \beta \frac{H_{1}+H_{2}-z}{H_{1}}\right)}{\cos \left(\lambda_{n} \alpha\right)} H_{1} \leq z \leq H_{2}\end{cases}
$$

The constant is the $n$th positive root of the following equation:

15. $\cos \theta-p \cos (q \theta)=0$

Also, according to the definition of consolidation, the degree of consolidation can be obtained by $U=S_{\mathrm{t}} / S_{\mathrm{f}}$.

To illustrate the settlement property, the displacement of both layers was analysed.

\section{Determination of calculation parameters}

With the equations above, the pore pressure can be calculated at any points of the whole layered system. A section profile of an under-construction highway was chosen to conduct a settlement analysis. The selected Xingercun-Dongerqu highway is located in Shaoxing city in the Hangzhou Bay area (marked green in Figure 3). The values for various parameters collected from the field investigation and laboratory tests are shown in Table 1 . The laboratory tests included triaxial shear test, oedometer tests and permeability test according to the Test Methods of Soils for Highway Engineering (RIHMT, 2007). The parameters of consolidation were calculated by Terzaghi's consolidation theory.

In the calculation, the filling height and width of the embankment were 4 and $35 \mathrm{~m}$, respectively. In the real situation, the additional 
Table 1. Parameters of soil for layers

\begin{tabular}{|c|c|c|c|c|c|c|c|c|c|c|}
\hline Material & $\begin{array}{c}\text { Soil } \\
\text { height: } \mathrm{m}\end{array}$ & $\begin{array}{c}\text { Wet } \\
\text { density, } \\
\rho: \mathrm{kg} / \mathrm{m}^{3}\end{array}$ & $\begin{array}{c}\text { Young's } \\
\text { modulus, } \\
E: \mathrm{kPa}\end{array}$ & $\begin{array}{c}\text { Poisson's } \\
\text { ratio, } v\end{array}$ & $\begin{array}{c}\text { Cohesion, } \\
\text { c: kPa }\end{array}$ & $\begin{array}{c}\text { Friction } \\
\text { angle, } \\
\phi:^{\circ}\end{array}$ & $\begin{array}{c}\text { Dilation } \\
\text { angle: } \\
\psi:^{\circ}\end{array}$ & $\begin{array}{l}\text { Permeability } \\
\text { coefficient, } \\
k: \mathrm{cm} / \mathrm{s}\end{array}$ & $\begin{array}{c}\text { Coefficient of } \\
\text { consolidation volume } \\
\text { compressibility, } M_{\mathrm{v}} \text { : } \\
\mathrm{MPa}^{-1}\end{array}$ & $\begin{array}{c}\text { Consolidation } \\
\text { coefficient, } C_{\mathrm{v}} \\
10^{-6} \mathrm{~m}^{2} / \mathrm{s}\end{array}$ \\
\hline Embankment & 4.0 & 1800 & 25000 & 0.20 & 1 & 30 & 0 & I & I & l \\
\hline $\begin{array}{l}\text { Silty sand of } \\
\text { upper layer }\end{array}$ & 25 & 1870 & 10000 & 0.35 & 8 & 29 & 0 & $1.1 \times 10^{-5}$ & 0.128 & 3.20 \\
\hline $\begin{array}{l}\text { Soft soil of } \\
\text { lower layer }\end{array}$ & 15 & 1930 & 8000 & 0.35 & 15 & 26 & 0 & $7.2 \times 10^{-5}$ & 0.313 & 0.51 \\
\hline
\end{tabular}

stress varied at different depths. The stress value at points at the surface, the bottom and the interface of the double-layered system was calculated by Boussinesq's solution. In each layer, the correlation between stress and depth was assumed as a linear variation (Zhu and Yin, 2005). The error between the assumption of a linear variation in layers and Boussineq's solution was small in the calculation of consolidation.

\section{Verification}

To verify the result, the finite-element method and field monitoring data were used to compare the outcome.

Figure 7 shows the geometry of the embankment and doublelayered foundation. As shown, a $35 \mathrm{~m}$ wide embankment with a height of $4 \mathrm{~m}$ and side slope of $1 \mathrm{~V}: 1.5 \mathrm{H}$ was constructed on a double-layered foundation. The double-layered foundation consisted of a silty sand layer of $25 \mathrm{~m}$ and a soft soil layer of $15 \mathrm{~m}$. In this study, the width of foundation was assigned with about three times that of the embankment to eliminate the effect of boundary conditions. Considering computational efficiency and the symmetry in the longitudinal direction of the embankment, the twodimensional (2D) finite-element model (FEM) for the embankment and double-layered foundation was simulated and analysed using the commercial software Abaqus 6.14. It was assumed that a stable layer lay below the soft soil layer. The fixed support condition was thereby used for the horizontal bottom boundary to completely restrict displacement. The displacement for the vertical planes of

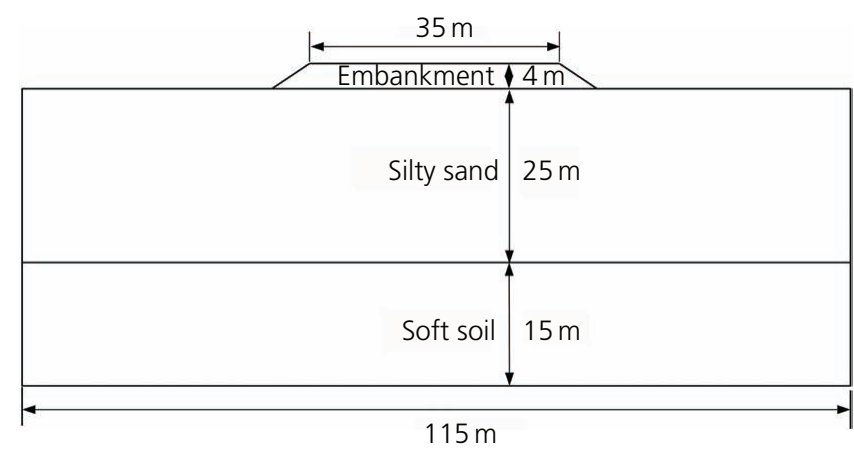

Figure 7. Schematics of embankment and double-layered foundation the 2D FEM were fixed in their corresponding normal directions. No displacement boundary was considered at the top plane of silty sand. Also, the ground water table is located at the top of the silty sand layer; consequently, it was set to zero pore pressure boundary and could be drained freely. The embankment and the soil of the foundation were simulated by a linear elastic perfectly plastic model with a Mohr-Coulomb failure criterion. Table 1 summarises the parameters about the embankment and soil. All the soil elements for the foundation were characterised using CPE4P, which showed a four-node plane strain quadrilateral, bilinear displacement and bilinear pore pressure. The elements for the embankment were characterised using CPE4, representing a four-node bilinear plane stress quadrilateral.

The embankment load was applied onto the top of the silty sand, after the establishment of the initial geostatic stress state and PWP. The load increased linearly with increasing filling height within the construction period, which was assumed to last for 3 months. A consolidation period after the embankment construction was applied in the 2D FEM. The consolidation was completed when the excess PWP fell below a specified value (i.e. $0.10 \mathrm{kPa}$ ) (Zhuang and Wang, 2018). Finer meshes were employed underneath and near the embankment, while coarser meshes were employed at the edges of the model. Figure 8 presents the mesh discretisation for the 2D FEM.

In the field, the settlement was monitored through the observation of settlement plates (Figure 9). During the construction period, observation was carried out every day.

The results of the analytical calculation and FEM simulation from the start of construction to 5 years later are shown in Figure 10, coupled with the field data collected in the first 2 years. Five years

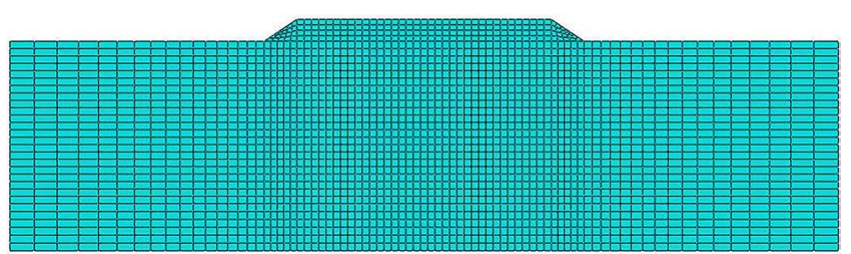

Figure 8. Mesh profile of 2D FEM 
Settlement mechanism and improvement of thick silty sand layer overlying mud

foundation

Li, Cheng, Fan, Qian and Chen

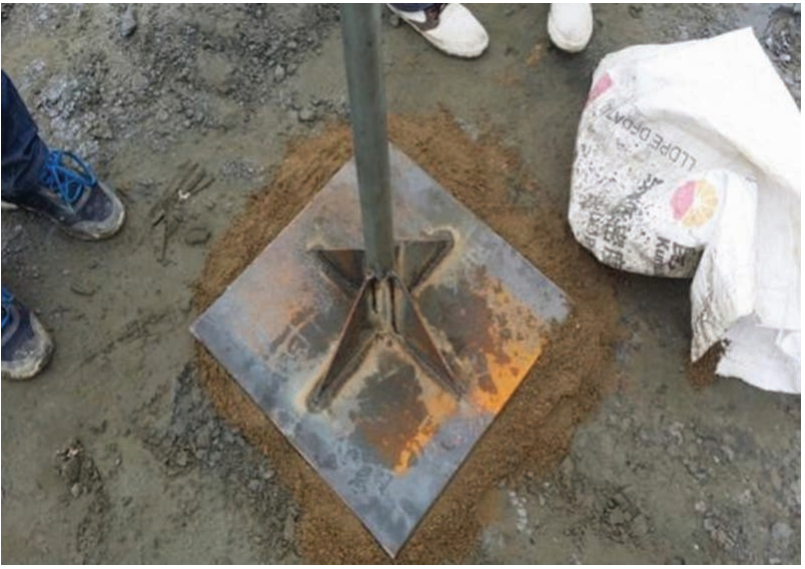

(a)

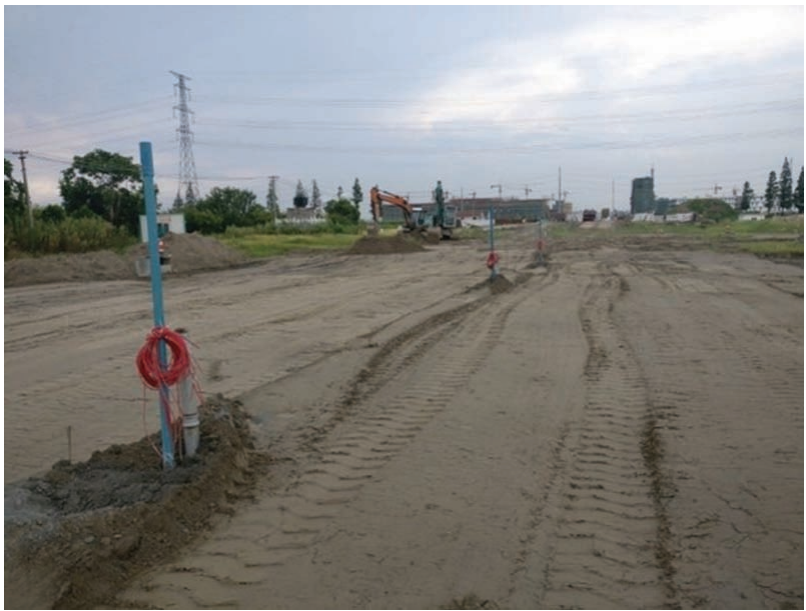

(b)

Figure 9. Settlement monitoring in the field: (a) settlement plate and rod; (b) setting of settlement plate and rod

after construction, the calculated settlement was about $0.25 \mathrm{~m}$. Although the result of the three methods had discrepancies, the trends of settlement build-up were similar. In the FEM simulation, compared with the result of the one-dimension analytical solution, the two-dimension condition was considered to have shown some influence. Meanwhile, during the actual construction process, the environment and conditions were more complicated due to the loading rate, climate change and construction machinery activities and so on; the difference between the calculation results and field data are not uncommon. Therefore, the analysis on the double layers with the analytical method is effective and can be used for further investigation.

From the results, it was found that the settlement developed at a highly increased rate during the construction period. However, in the post-construction period, the settlement still increased at a relative high rate. These results were consistent with the common phenomenon, which occurred during the field monitoring of the highway engineering.

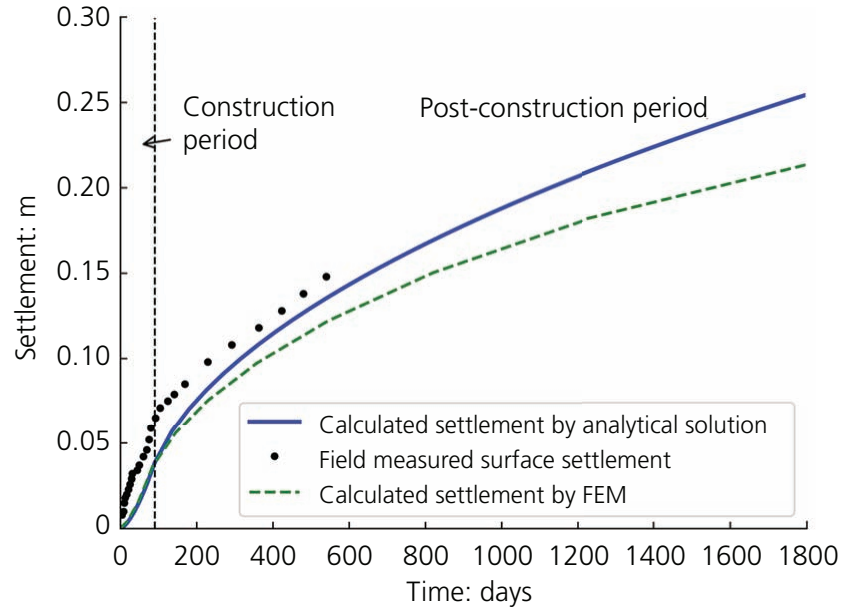

Figure 10. Calculated and measured settlement of the selected embankment section

Analysis of settlement and consolidation

To have further understanding as to why the settlement keeps rapidly increasing even 5 years after its construction, more analysis on settlement and consolidation was conducted using the analytical method. From the bar graph of the settlement (Figure 11), the displacement of both layers can be observed clearly. It was shown that although the thickness of the lower soft layer and the upper silty sand layer was 15 and $25 \mathrm{~m}$, respectively, the deformation of the lower layer has accounted for half of the total settlement after 10 years from the beginning of construction. Additionally, the total settlement at 15 years is $0.42 \mathrm{~m}$, which exceeds the allowable value of $30 \mathrm{~cm}$.

The increase of the consolidation degree for the two layers and the total foundation is shown in Figure 12. The consolidation degree increased over time due to the dissipation of the water pore pressure. Eventually, at the 15th year, the degree of consolidation for the upper layer was $82 \%$, while that for the

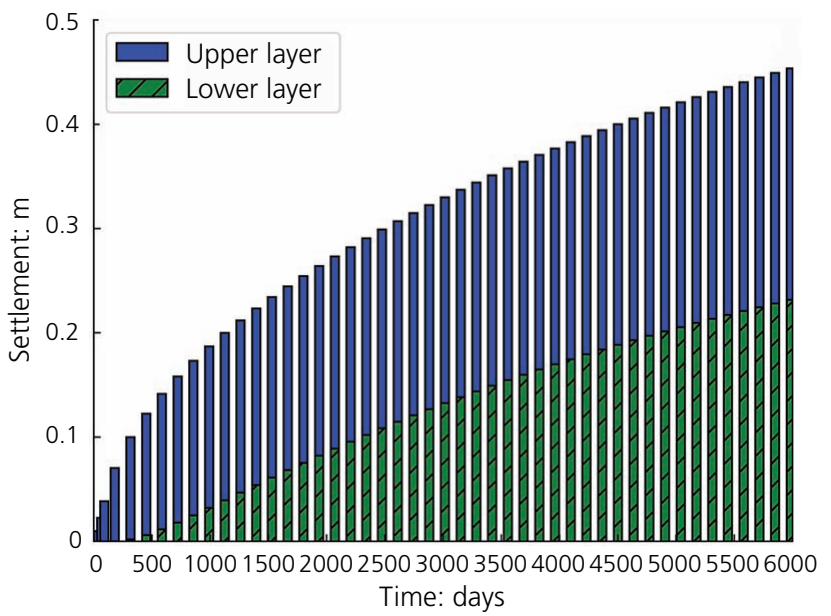

Figure 11. Settlement of two specific layers 
Settlement mechanism and improvement of thick silty sand layer overlying mud

foundation

Li, Cheng, Fan, Qian and Chen

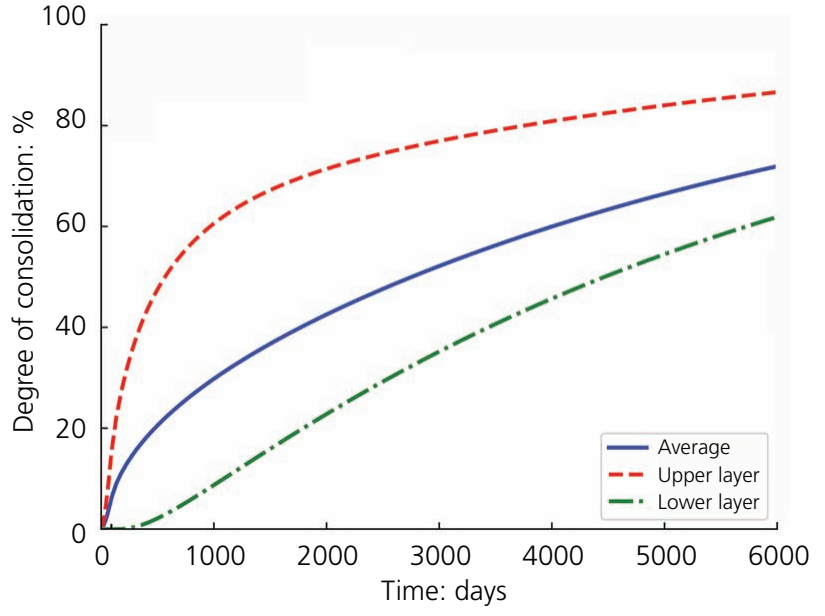

Figure 12. Consolidation degree of two layers

lower layer is around $60 \%$; the average consolidation degree reached $70 \%$. The development of settlement was caused by the interaction of the upper and lower layers of soil. Due to the long drainage channel, the PWP of the lower soil dissipated slowly.

For further detail, the excessive PWP distribution at different depths in the foundation is shown in Figure 13. At the end of construction (Figure 14(a)), only the PWP of the upper $10 \mathrm{~m}$ has changed. Figure 14(b) shows the PWP variation 5 years after the start of construction. It implies that the PWP of the whole depth had started to dissipate from the top to the bottom, and the PWP of the interface between two layers was about $45 \mathrm{kPa}$. The PWP at different depths kept decreasing and changed slightly at the interface. The PWP of the lower soft layer decreased more slowly than the upper layer in the next 5 years (Figure 14(c)). Finally, as shown in Figure 14(d), at 20 years after the start of construction the PWP at the bottom was less than $30 \mathrm{kPa}$, while at the interface it was about $20 \mathrm{kPa}$. The simulated results showed that the PWP of the whole double-layered system dissipated a lot over time. However, due to the low drainage rate of the lower layer, it would take more years to complete the consolidation process, which would result in a relatively fast-growing settlement even after 20 years of construction in practical situations.

To figure out when the consolidation could be completed, a longterm variation was simulated from the start of construction to 50 years later. A layer of foundation with the same parameters as of the upper silty sand layer was assumed in order to observe its influence on the lower soft soil layer. The results are shown in Figure 15. As previously mentioned, the consolidation degree of the lower layer grew more slowly than that of the upper layer. The degree of consolidation of the upper layer reached $90 \%$ at the 20th year, while that of the lower layer would take more than 20 years. As a result, it was predicted that the average consolidation of the entire foundation would require approximately 40 years to exceed $90 \%$. In a comparable case of $40 \mathrm{~m}$ thick homogeneous

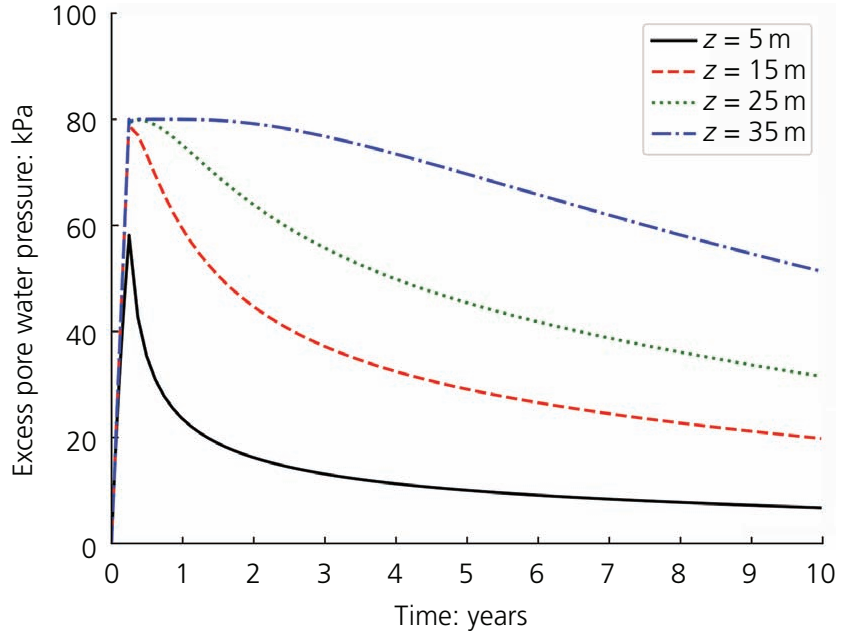

Figure 13. Distribution of excess PWP with time

silty sand ground, it only took about 15 years to reach $90 \%$. In terms of settlement, for double-layered ground, the final settlement was more than $0.60 \mathrm{~m}$. However, the settlement of a single-layer foundation reached $0.41 \mathrm{~m}$ in the 20th year and was kept stable in the following years. In fact, it is unnecessary to calculate the settlement for such a long time because the designed service time of highways is usually less than 20 years.

\section{Settlement analysis and suggestions}

Influence of layer thickness

Obviously, the geological conditions can vary within a small region. Assuming that the parameters of double soil layers remain unchanged, the only changeable parameter of the analysis was the thickness of the foundation. The analytical method was used to conduct a parametric study.

Therefore, the variation trend of the different thicknesses of double layers from the beginning of construction to 20 years later was calculated as shown in Figure 16. Intuitively, the thinner the layers, the smaller the final settlement value. For further study, the specific thickness of the double layers was changed to illustrate the phenomenon. When $\mathrm{H}_{2}$ was less than $10 \mathrm{~m}$, the settlement tended to be stable after 10 years of development. However, when $\mathrm{H}_{2}$ was more than $15 \mathrm{~m}$, the trend for $\mathrm{H}_{2}$ was still steep 10 years later. Considering that the lower layer was more sensitive to total settlement and consolidation than the upper one, reducing the thickness of the lower layer was more effective. This concept could be significant for engineers to solve problems in areas with the same double-layered geological conditions.

\section{Filling materials}

Another solution to decrease the settlement of the embankment is to reduce the upper loading on the foundation. For instance, foamed concrete and expanded polystyrene (EPS) are selected as lightweight materials commonly used in embankment construction 
Settlement mechanism and improvement of thick silty sand layer overlying mud

foundation

Li, Cheng, Fan, Qian and Chen

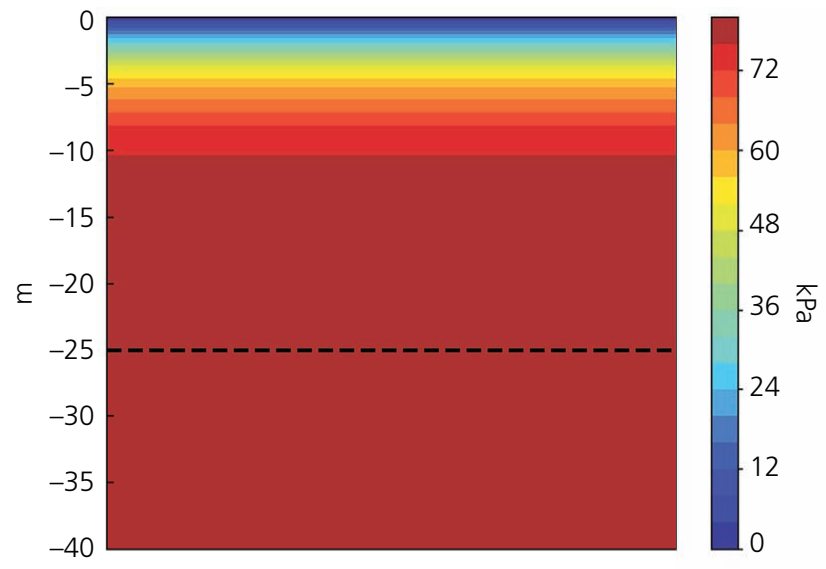

(a)

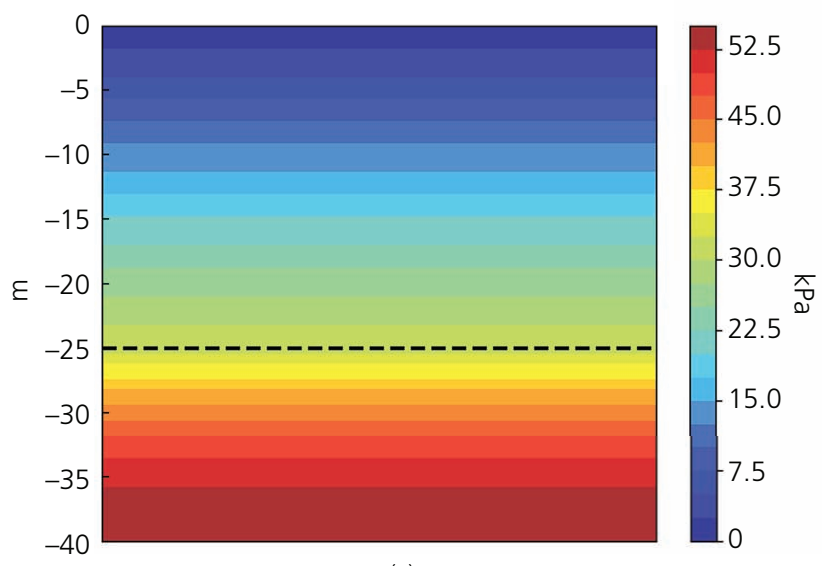

(c)

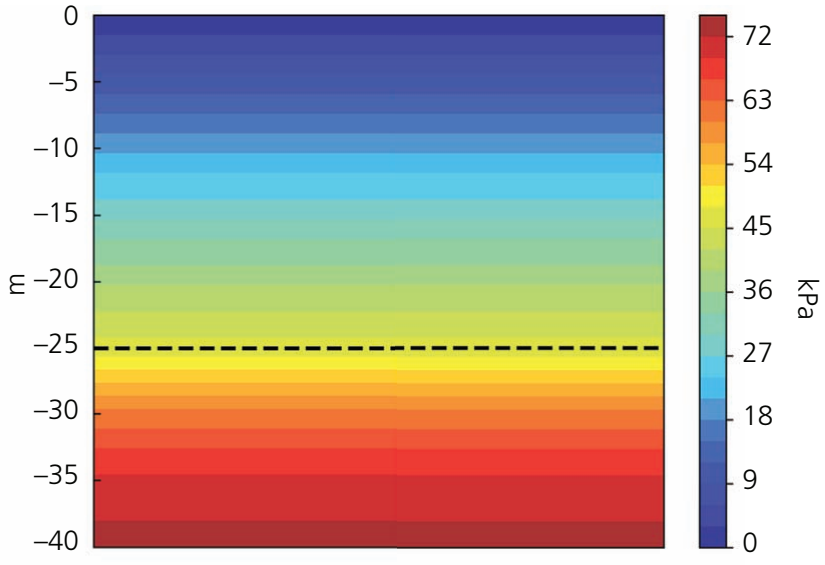

(b)

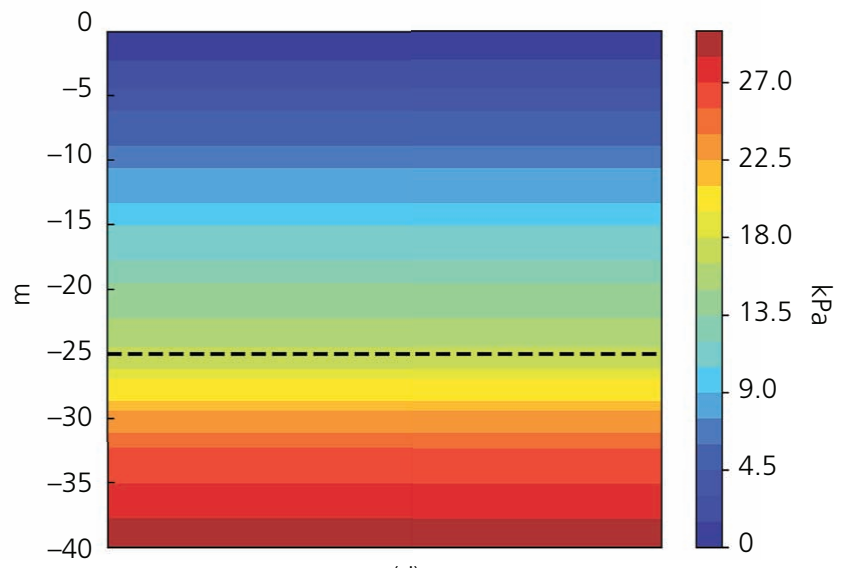

(d)

Figure 14. Excess pore pressure distribution of the foundation: (a) $t=90$ days (end of construction); (b) $t=5$ years; (c) $t=10$ years; (d) $t=20$ years

(Farnsworth et al., 2008). Foamed concrete is defined as a light cellular concrete which can also be classified as a lightweight

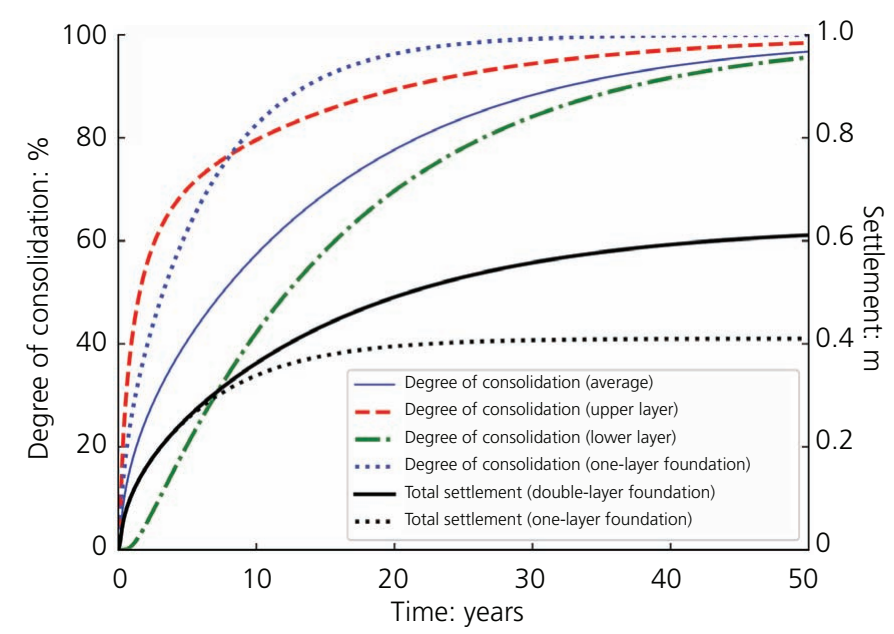

Figure 15. Long-term settlement and degree of consolidation filler (density of $400-1850 \mathrm{~kg} / \mathrm{m}^{3}$ ) with random air voids created from the mixture of foam agents in mortar (Sun et al., 2018).

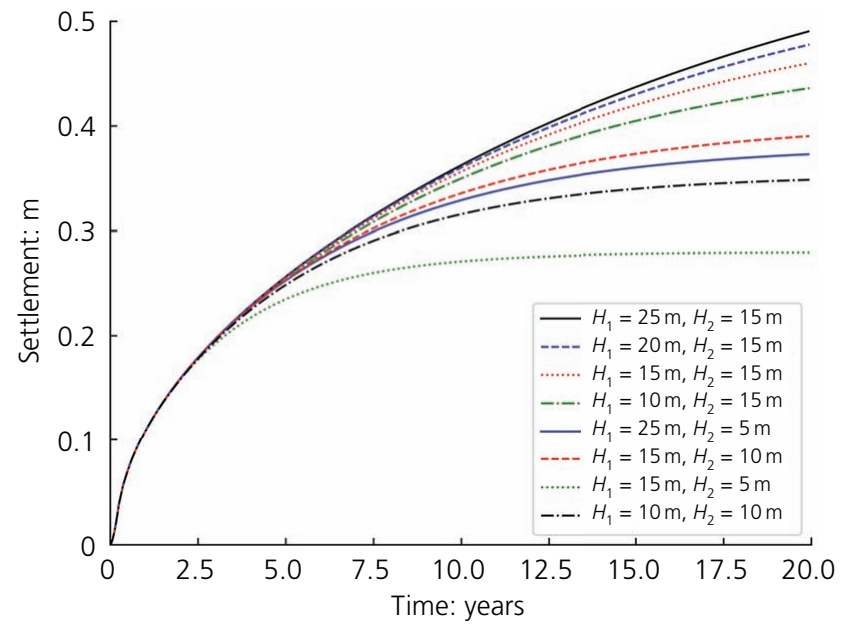

Figure 16. Development of settlement with different thickness of double layers 
Meanwhile, the density of EPS ranges from 12 to $35 \mathrm{kN} / \mathrm{m}^{3}$, accounting for as little as $1 / 100$ of the conventional fill materials. However, the cost of EPS construction is very high. Mixtures of EPS particles and soil can be applied in roads due to better engineering properties and lower prices.

In this study, some cases of using light materials were assumed to reduce the influence caused by settlement. The calculation process is as follows:

16.

$$
\alpha=\frac{h d_{1}+\left(H^{\prime}-h\right) d_{\mathrm{s}}}{H^{\prime} d_{\mathrm{s}}}
$$

where $\alpha$ is the modification coefficient of settlement with replacement, $h$ is the thickness of replaced lightweight materials, $H^{\prime}$ is the entire height of the embankment filling, $d_{\mathrm{s}}$ is the density of the original embankment soil and $d_{1}$ is the density of replaced lightweight materials. Then, the modified final settlement, $S_{\mathrm{f}}^{\prime}$, can be solved with the coefficient.

17. $S_{\mathrm{f}}^{\prime}=\alpha S_{\mathrm{f}}$

The mean density of different materials was considered in the calculation to comprehend the effect on the total settlement. Thus, the values for EPS, foamed concrete and EPS particles with soil were 20,900 and $1200 \mathrm{~kg} / \mathrm{m}^{3}$, respectively. Figure 17 shows the coefficient of final settlement for different alternative materials for embankment filling. Due to its light weight, EPS can contribute to the dramatic reduction of deformation. When $2 \mathrm{~m}$ of soil is replaced by EPS, the coefficient is reduced to less than 0.50 , which means that the total settlement could be reduced to half of the original. For foamed concrete, the entire embankment should

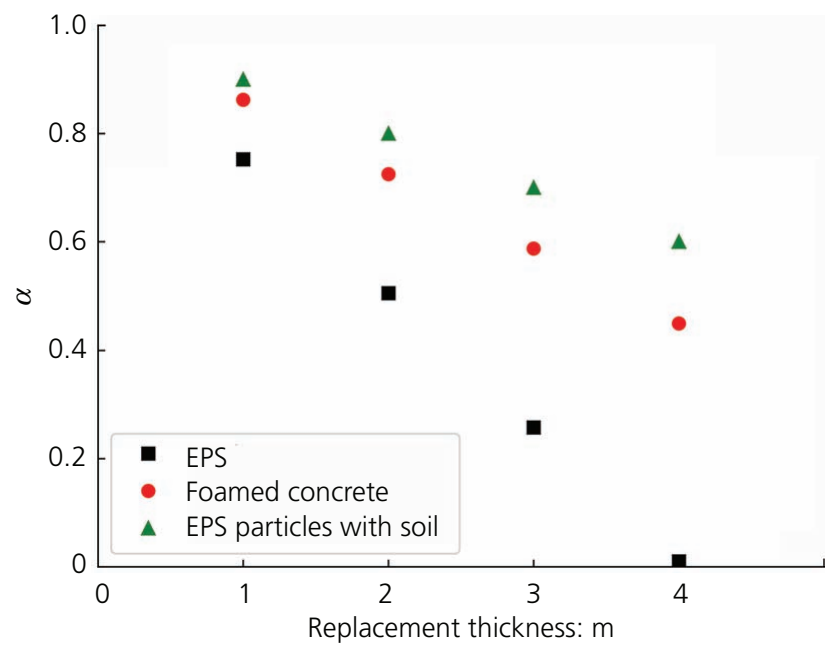

Figure 17. The coefficient of final settlement with different thicknesses for different alternative materials be replaced to decrease the settlement by half. EPS particles with soil could reduce the deformation by $40 \%$ when the whole embankment is replaced. When $4 \mathrm{~m}$ of the total height of embankment is replaced by EPS, the load can even be ignored. However, the cost and difficulties of the construction process are more important aspects for the engineers.

\section{Ground improvement with soil-cement columns}

In the Hangzhou Bay area, the common ground improvement techniques include vacuum preloading, dynamic compaction, deep mixing methods, jet grouting piles and so on. The previous studies and application illustrate that vacuum preloading and dynamic compaction can strengthen the soil less than $10 \mathrm{~m}$ below ground (Karunawardena et al., 2014). However, the dominant factor that should be considered is the properties of lower layer, which is more than $15 \mathrm{~m}$ below the surface of ground. Deep soil mixing and jet grouting methods are widely used in soft layers. Researchers have conducted studies to demonstrate a method that predicts the consolidation settlement of soft soil foundation improved by float soil-cement columns (Gong et al., 2015). This method was used to work out the application of soil-cement for strengthening the double layers. The core issue is to work out the equivalent consolidation coefficient of the ground improved by the soil-cement column, as the parameter $A$, to replace the original consolidation coefficient, $C_{\mathrm{v} 1}$ or $C_{\mathrm{v} 2}$, of the upper or lower layer, respectively. The equation is as follows:

18. $A=\frac{k_{\mathrm{v} 1} \overline{E_{S}(r)}\left(n^{2}-1+Y\right)}{\gamma_{w}\left(n^{2}-1\right)}$

where $k_{v 1}$ is the vertical permeability of soil, $\overline{E_{\mathrm{s}}(r)}$ is the average constrained modulus of the surrounding soil, $n=\frac{r_{\mathrm{e}}}{r_{\mathrm{e}}}$ is the radius ratio and $Y=\frac{E_{\mathrm{C}}}{E_{\mathrm{s}}(r)}$ is the constrained modulus ratio of the soil-cement column to the surrounding soil. $R_{\mathrm{e}}$ and $r_{\mathrm{c}}$ are the space between the columns and the diameter of a single column, respectively. $E_{\mathrm{c}}$ is the constrained modulus of columns. The parameters of soil-cement columns considered in the calculation are shown in Table 2, according to the real design of the engineering, and calculated according to the literature (Gong et al., 2015).

The ground improvement using three patterns of the same soil-cement columns was analysed, and the results are shown in Figure 18. From the start of construction to 20 years later, the settlement of the overall improved foundation is $0.21 \mathrm{~m}$. Compared with the original foundation, due to the $40 \mathrm{~m}$ long columns, the settlement has been reduced by more than half.

Table 2. Parameters of soil-cement columns in improvement of ground

\begin{tabular}{lccc}
$\begin{array}{l}\text { Diameter of } \\
\text { columns, } \\
\boldsymbol{r}_{\mathrm{c}: \mathrm{m}}\end{array}$ & $\begin{array}{c}\text { Space } \\
\text { between } \\
\text { columns, } \boldsymbol{r}_{\mathrm{e}}: \mathbf{m}\end{array}$ & $\begin{array}{c}\text { Radius } \\
\text { ratio, } \boldsymbol{n}\end{array}$ & $\begin{array}{c}\text { Constrained } \\
\text { modulus of }\end{array}$ \\
\hline 0.60 & 1.60 & 7.1 & 300 \\
columns, $\boldsymbol{E}_{\mathrm{c}}: \mathbf{M P a}$
\end{tabular}


However, strengthening the whole double layers by the deep mixing method or jet grouting may have a high cost. Therefore, engineers need to evaluate the economic feasibility of treating only one layer with soil-cement columns. After 20 years, the final ground settlement of the improved upper layer was $0.40 \mathrm{~m}$, while that of the improved lower layer was $0.37 \mathrm{~m}$. However, in the first 15 years, the deformation of the foundation of the improved upper layer was less than that of the improved lower layer. In other words, the ground settlement of the improved lower layer grew more gently. It can be easily explained that the columns increased the compressive modulus and reduced the permeability of the original layer. Since the initial constrained modulus was at a relatively low level, the addition of columns would have a more significant effect on the reduction of deformation.

To observe the consolidation behaviour of the treated foundation in different parts, the consolidation degree was compiled. At the end of the 20th year, the consolidation degree of the original foundation was $77.6 \%$, and yet, the consolidation process was not completed. The consolidation variation of the improved upper-layer foundation was similar to that of the untreated foundation. Combined with the settlement analysis, it can be concluded that the improvement of the upper layer might result in the reduction of settlement by increasing the composite modulus, which had limited influence on the settlement rate. Variation of foundation settlement improved by soil-cement columns in different parts is shown in Figure 19. If the whole double-layered system ground is modified by soil-cement columns, the overall consolidation degree can exceed $80 \%$ in the 8th year, and finally attain $97.60 \%$ at the end of the 20th year, which would make a dramatic change due to the variation of the average constrained modulus and hydraulic conductivity. The tendency of the consolidation degree for improved lower-layer foundation was close to that of entire improved foundation, and the final value was $96.5 \%$, which shows a high degree of consolidation. In other words, the improved lower-layer foundation

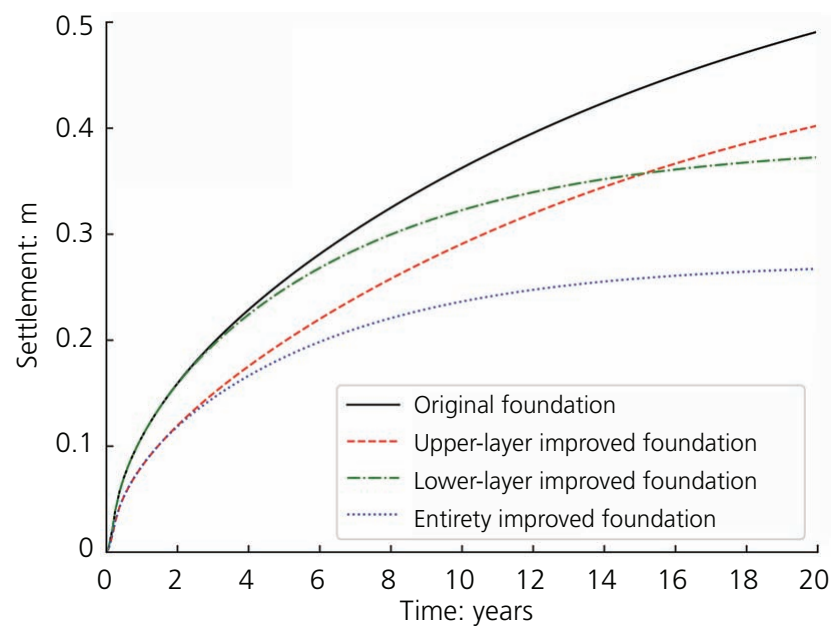

Figure 18. Variation of foundation settlement improved by soil-cement columns in different parts had a positive effect on both the reduction of settlement and acceleration of consolidation for the foundation system. The low permeability and compressive modulus of the lower layer in the foundation have adverse effects on consolidation. The main measure taken into consideration by engineers should be to modify these characteristics.

Another issue that should be noticed was that the strengthened thickness of the lower layer was less than $10 \mathrm{~m}$, while the thickness of the upper layer was $25 \mathrm{~m}$. In certain cases, costs should be carefully considered. Generally, improving only the lower layer was a more efficient and economical way to solve similar ground problems. The settlement variation in the different layouts of the soil-cement columns is shown in Figure 20. It is reasonable that the smaller the space between the columns or the larger the diameter of the column, the smaller the final settlement. However, it is necessary to conduct research to understand how these parameters affect the final engineering properties.

The key parameters of foundation improved by the columns are the constrained modulus ratio, $n$, and the radius ratio, $Y$, which are affected by $r_{\mathrm{e}}, r_{\mathrm{c}}$ and $E_{\mathrm{c}}$. The settlement decreased with the increase of $n$ or $Y$. When $n=7.10$ and $E_{\mathrm{c}}=300 \mathrm{MPa}$, the final settlement was $0.37 \mathrm{~m}$. When $n$ was decreased to 4.00 , the settlement was reduced to $0.30 \mathrm{~m}$. Meanwhile, a lower $E_{\mathrm{c}}$ would cause a larger settlement, and the settlement value was $0.36 \mathrm{~m}$ for $E_{\mathrm{c}}=200 \mathrm{MPa}$. According to the final settlement limit of $30 \mathrm{~cm}$ criterion, considering the previous deformation during the construction period, a settlement less than $0.35 \mathrm{~m}$ in 20 years can be acceptable. If the width of road ground is $50 \mathrm{~m}$, about 7,10 and 13 piles are required for each row of $n=7.10$, 5.40 and 4.00 in the field, respectively. In the first 4 years, the settlement trend for the different layout and properties of piles is similar because in the first stage, the settlement mainly comes from the upper layer. When $n=4$ and $E_{\mathrm{c}}=300 \mathrm{MPa}$, the settlement after construction is less than $10 \mathrm{~cm}$.

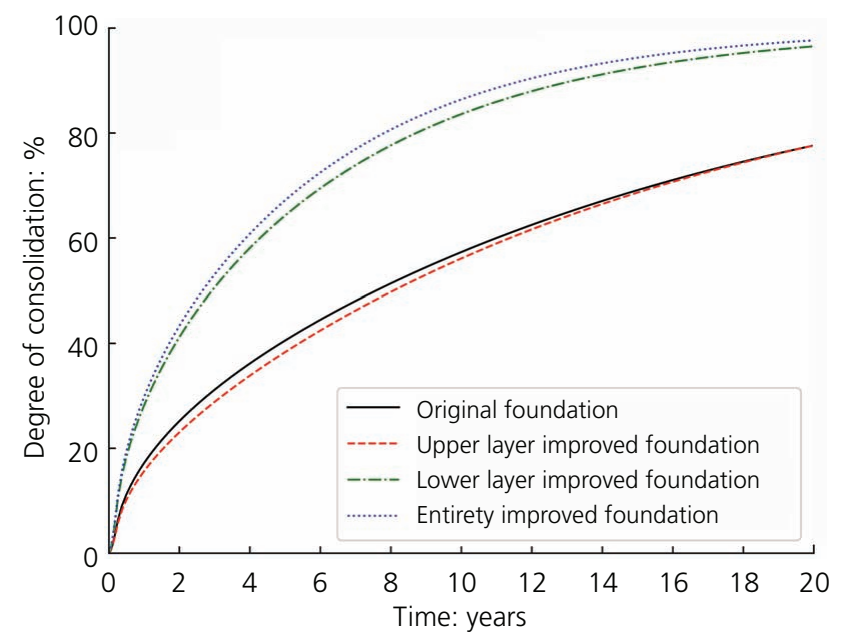

Figure 19. Variation of average consolidation for foundation with different parts improved by soil-cement 


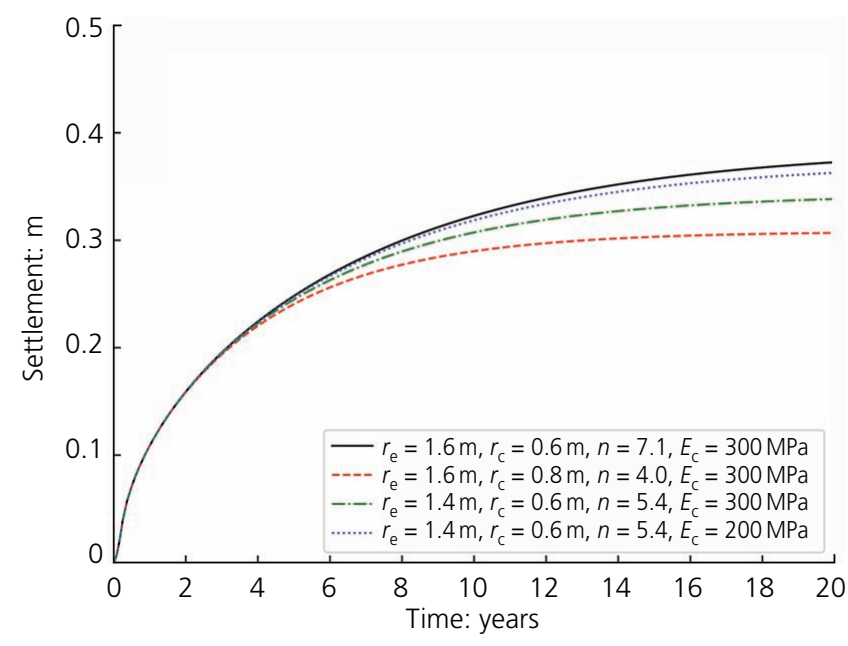

Figure 20. Variation of settlement with different layouts of cement piles

\section{Conclusion}

In this study, the field data analysis and calculation of the settlement of a typical embankment in the Hangzhou Bay region were conducted. The following conclusions are drawn.

- It was observed that the settlement of the highway embankments built in the Hangzhou Bay area has been increasing for more than 10 years. The settlement of some monitoring points was more than $2.50 \mathrm{~mm}$ per month. And many cracks and potholes were caused by the differential settlement.

a From the calculation, at the 15 th year, the degree of consolidation for the upper layer was $82 \%$ while that for the lower layer was around $60 \%$, which contributed to the average consolidation degree of $70 \%$. The long-term behaviour of the embankment settlement was mainly caused by the lower layer. Meanwhile, during the construction period and the first stage of preloading or traffic, the variation trend of the lower layer kept on increasing at a slow rate.

- Light materials were applied to reduce the influence caused by the settlement; using light materials was assumed to reduce the influence caused by the settlement. When $4 \mathrm{~m}$ of the total height of the embankment was replaced by EPS, the load could even be ignored.

- When the ground improvement with soil-cement columns is under consideration, the improvement of the lower layer will have a more positive influence on the whole double-layered foundation. In the first 4 years, the settlement trend for the different layouts and properties of piles was similar because in the first stage, the settlement mainly came from the upper layer. Additionally, a lower radius ratio and a more constrained modulus of columns can reduce the post-construction settlement. When $n=4$ and $E_{\mathrm{c}}=300 \mathrm{MPa}$, the settlement after construction was less than $10 \mathrm{~cm}$.

- With the analytical method, it is convenient and efficient to calculate and analyse the settlement at different periods, which is significant for design.

\section{Acknowledgements}

The authors would like to acknowledge the financial support by the Science and Technology Foundation of Zhejiang Communications (No.2014H13) and Research Startup Foundation of Suzhou University of Science and Technology (No.332111101).

\section{REFERENCES}

Burd HJ and Frydman S (1997) Bearing capacity of plane-strain footings on layered soils. Canadian Geotechnical Journal 34(2): 241-253, https://doi.org/10.1139/t96-106.

Eshkevari SS, Abbo AJ and Kouretzis G (2019) Bearing capacity of strip footings on sand over clay. Canadian Geotechnical Journal 56(5): 699-709, https://doi.org/10.1139/cgj-2017-0489.

Farnsworth CB, Bartlett SF, Negussey D and Stuedlein AW (2008) Rapid construction and settlement behavior of embankment systems on soft foundation soils. Journal of Geotechnical \& Geoenvironmental Engineering 134(3): 289-301, https://doi.org/10.1061/(ASCE)10900241(2008)134:3(289).

Fourie $A B$ and Tshabalala $L$ (2005) Initiation of static liquefaction and the role of $\mathrm{K}_{0}$ consolidation. Canadian Geotechnical Journal 42(3): 892-906, https://doi.org/10.1139/t05-026

Gong XN, Tian XJ and Hu WT (2015) Simplified method for predicating consolidation settlement of soft ground improved by floating soilcement column. Journal of Central South University 22(7): 2699-2706, https://doi.org/10.1007/s11771-015-2800-7.

Griffiths DV (1982) Computation of bearing capacity on layered soil. In Numerical Methods in Geomechanics: Edmonton 1982 (Eisenstein Z (ed.)). Balkema, Rotterdam, the Netherlands, vol. 1, pp. 163-170.

Hanna AM and Meyerhof GG (1980) Design charts for ultimate bearing capacity of foundations on sand overlying soft clay. Canadian Geotechnical Journal 17(2): 300-303, https://doi.org/10.1016/0148-9062(81)91116-5.

Huang W, Fityus S, Bishop D, Smith D and Sheng D (2006) Finite-element parametric study of the consolidation behavior of a trial embankment on soft clay. International Journal of Geomechanics 6(5): 328-341, https://doi.org/10.1061/(asce)1532-3641(2006)6:5(328).

Karunawardena A and Toki M (2014) Performance of highway embankments constructed over Sri Lankan peaty soils. International Journal of Integrated Engineering 6(2): 75-83.

Kato S, Ishihara K and Towhata I (2001) Undrained shear characteristics of saturated sand under anisotropic consolidation. Soils and Foundations 41(1): 1-11, https://doi.org/10.3208/sandf.41.1.

Kenny MJ and Rawes KZ (1997) The bearing capacity of footings on a sand layer overlying soft clay. Geotechnique 47(2): 339-345, https:// 10.1680/geot.1999.49.4.553.

Kim P, Kim HS, Pak CU et al. (2020) Analytical solution for onedimensional nonlinear consolidation of saturated multi-layered soil under time-dependent loading. Journal of Ocean Engineering and Science 6(1): 21-29, https://doi.org/10.1016/j.joes.2020.04.004.

Li S, Huang X and Zeng C (2017) Performance of an embankment foundation with sand over clay: experimental and numerical analyses. International Journal of Geomechanics 17(6): 06016038, https://doi.org/10.1061/ (ASCE)GM.1943-5622.0000841.

Liu Y, Xia X, Jia J and Cai T (2017) Morphological evolution of Jinshan Trough in Hangzhou Bay (China) from 1960 to 2011. Estuarine, Coastal and Shelf Science 198: 367-377, https://doi.org/10.1016/j. ecss.2016.11.004.

Meyerhof GG (1974) Ultimate bearing capacity of footings on sand layer overlying clay. Canadian Geotechnical Journal 11(2): 223-229, https://doi.org/10.1139/t74-018.

Miao L, Wang X. and Kavazanjian E (2008) Consolidation of a doublelayered compressible foundation partially penetrated by deep mixed columns. Journal of Geotechnical and Geoenvironmental Engineering 134(8): 1210-1214, https://doi.org/10.1061/(ASCE)1090-0241(2008) 134:8(1210). 
Geotechnical Research

Volume 9 Issue 1
Settlement mechanism and improvement

of thick silty sand layer overlying mud

foundation

Li, Cheng, Fan, Qian and Chen
Nguyen HBK, Rahman MM and Fourie AB (2017) Undrained behaviour of granular material and the role of fabric in isotropic and $\mathrm{K} 0$ consolidations DEM approach. Géotechnique 67(2): 153-167, https://doi.org/10.1680/ jgeot.15.P.234

Okamura M, Takemura J and Kimura T (1997) Centrifuge model tests on bearing capacity and deformation of sand layer overlying clay. Soils and Foundations 37(1): 73-88, https://doi.org/10.3208/sandf.37.73.

Rahman MM, Nguyen HBK and Rabbi ATMZ (2018) The effect of consolidation on undrained behaviour of granular materials: experiment and DEM simulation. Geotechnical Research 5(4): 199-217, https://doi.org/10.1680/jgere.17.00019.

RIHMT (Research Institute of Highway Ministry of Transport) (2007) Test Methods of Soils for Highway Engineering. China Communications Press, Beijing, China (in Chinese).

Schiffmann R and Stein J (1970) One-dimensional consolidation of layered systems. Journal of Soil Mechanics \& Foundations 96(4): 1499-1504, https://doi.org/10.1061/JSFEAQ.0001453.

Sun C, Zhu Y, Guo J, Zhang Y and Sun G (2018) Effects of foaming agent type on the workability, drying shrinkage, frost resistance and pore distribution of foamed concrete. Construction and Building Materials 186: 833-839, https://doi.org/10.1016/j.conbuildmat.2018.08.019.

Terzaghi K and Peck RB (1948) Soil Mechanics in Engineering Practice. John Wiley and Sons, New York, NY, USA.

Tyurin DA and Nevzorov AL (2017) Numerical simulation of long-term peat settlement under the sand embankment. Procedia Engineering 175 51-56, https://doi.org/10.1016/j.proeng.2017.01.014.
Xie X, Xie K and Gao X (1999) Theory of one dimensional consolidation of two-layered soil with partially drained boundaries. Computers and Geotechnics 24(4): 265-278, https://doi.org/10.1016/S0266-352X(99) 00012-9.

Yadav SK, Ye G, Khalid U and Fukuda M (2019) Numerical and centrifugal physical modelling on soft clay improved with floating and fixed sand compaction piles. Computers and Geotechnics 115: article 103160, https://doi.org/10.1016/j.compgeo. 2019.103160.

Zheng G, Zhou HZ, Cheng XS, Liu JJ and Zheng SQ (2016) Numerical analysis of the ultimate bearing capacity of the layered soil foundation with sand overlying clay. Rock and Soil Mechanics 37(5): 1475-1485, https://doi.org/10.16285/j.rsm.2016.05.032.

Zhu G and Yin J (1999) Consolidation of double soil layers under depthdependent ramp load. Geotechnique 49(3): 415-421, https://doi.org/ 10.1680/geot.1999.49.3.415.

Zhu G and Yin J (2005) Solution charts for the consolidation of double soil layers. Canadian Geotechnical Journal 42(3): 949-956, https:// doi.org/10.1139/t05-001.

Zhuang Y and Wang K (2018) Finite element analysis on the dynamic behavior of soil arching effect in piled embankment. Transportation Geotechnics 14: 8-21, https://doi.org/10.1016/j.trgeo. 2017.09.001.

ZIC (Zhejiang Institute of Communications) (2013) Code for Design of Highway Embankment on Soft Ground. China Communications Press, Beijing, China (in Chinese).

\section{How can you contribute?}

To discuss this paper, please submit up to 500 words to the editor at journals@ice.org.uk. Your contribution will be forwarded to the author(s) for a reply and, if considered appropriate by the editorial board, it will be published as a discussion in a future issue of the journal. 